\title{
Normal Aging Dampens the Link Between Intrusive Thoughts and Negative Affect in Reaction to Daily Stressors
}

\author{
Annette Brose \\ Max Planck Institute for Human Development
}

Martin Lövdén

Max Planck Institute for Human Development and

Karolinska Institute

\author{
Florian Schmiedek \\ Max Planck Institute for Human Development and German \\ Institute for International Educational Research
}

\author{
Ulman Lindenberger \\ Max Planck Institute for Human Development
}

\begin{abstract}
We charted daily variations in intrusive thoughts to gain access to adult age differences in affective reactivity to daily stressors. On 100 days, 101 younger and 103 older adults reported stressors, intrusive thoughts, and negative affect. Although increments in intrusive thoughts were similar in both age groups on days with stressors, older adults' negative affect increased less than younger adults' on such days. In addition, (a) levels of intrusive thoughts and negative affect across study time were positively associated; (b) days with increased thoughts were days with increased negative affect; and (c) experiencing above-average intrusive thoughts about stressors strengthened affective reactions to stress. Relative to younger adults, all three associations were reduced in older adults. We tentatively conclude that normal aging dampens the stress-induced link between intrusive thoughts and affect. This dampening may contribute to preserved affective well-being and reduced affective reactivity to daily stress in old age.
\end{abstract}

Keywords: intraindividual variability, daily stress, negative affect, intrusive thoughts

After having an argument with a friend, mood may be disturbed. In addition, one may remember earlier disagreements about similar issues or consider one's handling of the conflict. Some of such thoughts may result in an additional impairment of mood, others may help resolve the problem and contribute to mood repair. Put differently, experiencing a subjectively perturbing event elicits a cascade of multifaceted reactions operating in a transactional manner (Lazarus, 2000; Tennen, Affleck, Armeli, \& Carney, 2000); as in the example, mood and ongoing concerns may interact. In general, this observation applies to how people cope with major life events, but also relates to daily stressors, both having an impact on psychological and physical well-being (Stone \& Neale, 1984; Zautra, 2003).

This study investigated reactions to daily stress as a multifaceted phenomenon in younger and older adults and from a within-person perspective. It addressed whether, and how, affective states and intrusive thoughts co-occur with the experience of negative events in daily life, henceforth termed daily stressors. With its tripartite focus on stressors, intrusive thoughts, and negative affect, the study extends its scope beyond earlier within-person investigations of daily stress in aging research that mainly focused on bivariate within-person relations (for exceptions, see Birditt, Fingermann, \& Almeida, 2005; Ong, Bergeman, Bisconti, \& Wallace, 2006).

Evidence is accumulating that competencies optimizing affective well-being improve across adulthood (e.g., Charles \& Carstensen, 2007). However, it is unclear how younger and older adults differ regarding their affective reactivity to daily stressors (e.g., Mroczek \& Almeida, 2004). We propose that the consideration of intrusive thoughts plays an important role in understanding age differences in affective reactivity to stress. Intrusive
This article was published Online First April 11, 2011.

Annette Brose and Ulman Lindenberger, Center for Lifespan Psychology, Max Planck Institute for Human Development, Berlin, Germany; Florian Schmiedek, Center for Lifespan Psychology, Max Planck Institute for Human Development, Berlin, Germany; German Institute for International Educational Research, Frankfurt am Main, Germany; Martin Lövdén, Center for Lifespan Psychology, Max Planck Institute for Human Development, Berlin, Germany and Aging Research Center, Karolinska Institute.

The COGITO Study was supported by the Max Planck Society, including a grant from the innovation fund of the Max Planck Society (M.FE.A.BILD0005); and the Sofja Kovalevskaja Award (to ML) of the Alexander von Humboldt Foundation donated by the German Federal
Ministry for Education and Research (BMBF). This article was revised while Ulman Lindenberger was a fellow at the Center for Advanced Study in the Behavioral Sciences at Stanford University. The authors thank the following persons for their important roles in conducting the COGITO Study: Colin Bauer, Gabriele Faust, Katja Müller-Helle, Birgit Heim, Annette Rentz-Lühning, Werner Scholtysik, Oliver Wilhelm, Julia Wolff, and a team of highly committed student research assistants. We also thank Nilam Ram and Michaela Riediger for helpful discussions regarding this manuscript, and Julia Delius for improving the English.

Correspondence concerning this article should be addressed to Annette Brose, Max Planck Institute for Human Development, Center for Lifespan Psychology, Lentzeallee 94, 14195 Berlin, Germany. E-mail: brose@mpib-berlin.mpg.de 
thoughts are repeatedly occurring thoughts that are often unwanted and difficult to control (Rachman, 1981). They may follow events and are also referred to as cognitive reactivity (Nezlek, 2005; Segerstrom, Stanton, Alden, \& Shortridge, 2003). Because intrusive thoughts and related phenomena may enhance negative affective states, they are described as a form of nonadaptive coping (Nolen-Hoeksema, Morrow, \& Fredrickson, 1993; Skinner, 2001). It is important to note that levels of intrusive thoughts and their negative consequences appear to decrease across adulthood (Erskine, Kvavilashvili, Conway, \& Myers, 2007). Therefore, this study investigated age group differences in intrusive thoughts and their relation to age group differences in affective reactivity to daily stressors. Intrusive thoughts were thoroughly examined, including their co-occurrence with daily stressors, and their general relation with negative affect.

\section{Affective Reactivity to Daily Stressors}

The notion that "bad events" are associated with "bad mood" is not just a layperson's belief but has been investigated extensively and empirically confirmed. This is often referred to as affective reactivity to stress and investigated as the within-person covariation or "coupling" between stress occurrence and affect (Bolger \& Zuckerman, 1995; Sliwinski, Almeida, Smyth, \& Stawski, 2009). Affective reactions are an integral part of the stress process because they reflect that events are appraised as a loss or threat; for example (Almeida, 2005), they initiate coping behavior, are subject to regulatory efforts, and change according to reappraisals (Carver \& Scheier, 1999; Folkman \& Moskowitz, 2004; Zautra, 2003).

\section{Adult Age Differences}

Assuming that habituation to repeated stimulus exposure occurs over time, one would predict that affective reactivity to daily stress decreases with advancing age (Lawton, Katz, \& Nesselroade, 1996). Such habituation may be mediated by improved coping abilities, such as an increased repertoire of strategies or more flexible use of strategies (Aldwin, 1994; Blanchard-Fields, 2007). In addition, an external orientation of locus of control (Lachman, 1986) and the necessity to adapt to increasingly unalterable losses (Baltes, 1987) may reduce affective reactivity. Developmental theories of affective functioning also suggest that older adults react less to daily stressors. For instance, older adults' greater emphasis of emotional goals and their higher motivation to maximize wellbeing, both predicted by socioemotional selectivity theory (Carstensen, Fung, \& Charles, 2003), may result in improvements in emotion regulation, which in turn may be beneficial when dealing with stress. Alternatively, decrements in affective reactivity can be interpreted as a consequence of declining cognitiveemotional complexity that promotes self-protective behavior and is characterized by lower levels of negative emotions (LabouvieVief, 2003).

Some empirical findings are in line with these theoretical expectations and point to a reduction of affective reactivity in old age. Self-reported emotion regulation skills improve across adulthood (Gross et al., 1997; Kessler \& Staudinger, 2009; Lawton, Kleban, Rajagopal, \& Dean, 1992), and older adults are quicker at regulating affective disturbances in daily life (Carstensen, Mayr,
Pasupathi, \& Nesselroade, 2000). However, when affective reactivity to daily stressors is measured directly, some findings challenge propositions of a reduction in older age. Evaluations of stressor severity and affective reactivity to daily stressors were sometimes shown to be lower in older compared with younger adults (Birditt et al., 2005; Stawski, Almeida, Lachman, Tun, \& Rosnick, 2010; Uchino, Berg, Smith, Pearce, \& Skinner, 2006), but also stronger (Mroczek \& Almeida, 2004), or invariant across age groups (e.g., Stawski, Sliwinski, Almeida, \& Smyth, 2008). Methodological differences across studies as well as the sampling of stressor types may contribute to a heterogeneous picture of findings (Röcke, Li, \& Smith, 2009; Stawski et al., 2008). For example, older adults show decreased reactivity in the domain of interpersonal stressors in particular (Neupert, Almeida, \& Charles, 2007). Potential explanations for invariant affective reactivity across age groups or an increase with age are that older adults may profit from avoiding negative events, which provides no advantage when stressors occur (Charles, Piazza, Luong, \& Almeida, 2009), or that a reduction in personal resources results in increased reactivity to daily stressors (Sliwinski et al., 2009).

In conclusion, this research field is faced by the challenge to explain the inconsistencies and to gain a better understanding of age group differences in the daily stress process of which negative affect is only one aspect. The approach of this study to broadening our understanding of age group differences in affective reactivity was to focus on one particular variable that is closely associated with experiencing stressful events, namely intrusive thoughts. As will be elaborated in the following section, intrusive thoughts accompany stressful events on a rather immediate time scale. They are a general indicator of concern and are closely related to negative affect. It is important to note that there are reasons to believe that the relation between the two variables becomes weaker with age. Thus, the tripartite investigation of stress, affect, and intrusive thoughts in the two age groups may shed light on important age group differences operating at the microlevel of the stress process. As the following will show, considering intrusive thoughts in the daily stress process strengthens the assumption of reduced affective reactivity in older adults.

\section{Intrusive Thoughts, Daily Stress, and Negative Affect}

Intrusive thoughts are one form of repetitive thoughts in the context of adjustment among others such as rumination or worry. The process of thinking attentively, repetitively, and frequently about oneself or one's world is common to these experiences (Segerstrom et al., 2003). The different terms' meanings vary (cf. Nolen-Hoeksema, Wisco, \& Lyubomirsky, 2008, for an overview); some characterize psychopathology (e.g., depression; Lyubomirsky \& Tkach, 2004; Nolen-Hoeksema et al., 1993), others describe a rather common phenomenon, for example, when people undergo life changes (Horowitz, 1985; Horowitz, Wilner, \& Alvarez, 1979). Intrusive thoughts are considered a maladaptive stress response (Janke \& Erdmann, 2002; Skinner, 2001) and a component of self-regulation when an important goal is blocked or when events threaten one's self (Kuhl \& Baumann, 2000; Martin, Tesser, \& McIntosh, 1993).

Thus, repetitive thoughts are portrayed as a trait-like disposition towards pathology, but also as a reaction to stress that is common and transient. Regarding the latter, empirical studies showed that 
intrusive thoughts and related phenomena are a common everyday phenomenon in non-clinical samples and without the observation of a stressor (Brewin, Christodoulides, \& Hutchinson, 1996). They were also shown to have state-like qualities and to be coupled with the occurrence of daily events (Moogle, Stawski, \& Sliwinski, 2008; Nezlek, 2005).

There are different models describing how repetitive thoughts, negative affect, and stressful events are linked. According to Nolen-Hoeksema et al. (1993), rumination occurs as a reaction to experiencing depressive symptoms. That is, negative affect may be elicited by stressful events and subsequently becomes the focus of attention. Other descriptions of repetitive thoughts assign them a mediating function, in the sense that an ongoing representation of stressors prolongs affective and physiological consequences of stress (Brosschot et al., 2006). Reasons for prolonged negative affect in the face of repetitive thoughts, independent of their content, are that such thoughts enhance mood-congruent recall, interfere with more constructive problem-solving behavior, and distort motivation and concentration (Lyubomirsky, Kasri, \& Zehm, 2003; Lyubomirsky, Sousa, \& Dickerhoof, 2006). Quite to the contrary, intrusive thoughts may also be one step in recovery from stress (Horowitz, 1985). Their immediate negative consequences may be inevitable, but the process in itself necessary and potentially adaptive as directing resources to some concern may lead to solutions.

The preceding led to the following decisions about how to measure intrusive thoughts in this study. In order to address the fact that intrusive thoughts may, but do not have to be concerned with particular events, we considered two types of intrusive thoughts: intrusive thoughts about particular stressors (referred to as stressor-related INTH), and intrusive thoughts without a clear link to specific stressors (unspecific INTH). The former were assessed in direct relation to the daily stressors that individuals reported. In addition, we attempted to assess intrusive thoughts such that a confounding with valence, in particular negative affect, was low. This allowed for an unambiguous interpretation of the relation between intrusive thoughts, negative affect, and daily stressors.

\section{Adult Age Differences}

Older adults are more susceptible to interference than younger adults in learning tasks (e.g., Hasher \& Zacks, 1988; Kliegl \& Lindenberger, 1993). Such interference proneness may also be relevant for subjectively experiencing an intrusive thought. A few studies suggest that older adults either report intrusive thoughts equally often as younger adults (Wrosch \& Heckhausen, 2002), or less often (Erskine et al., 2007; McConatha, Leone, \& Armstrong, 1997). Furthermore, older adults report less task-unrelated thoughts (Giambra, 1989) and make less efforts to suppress intrusive thoughts (Erskine et al., 2007), which might indicate that they do not have as many unwanted thoughts in the first place or that they do not perceive them as threatening. One explanation for lower levels of self-reported intrusive thoughts in older adults is that fulfilling relatively automatic tasks such as walking requires more resources in older adults, leaving less mental capacity available for additional thoughts (Erskine et al., 2007). In addition, evaluations of intrusive thoughts may change with age and increasingly lose their threatening character. For instance, older adults are assumed to profit from flexible goal adjustment rather than tenacious goal pursuit (Brandtstädter, Wentura, \& Rothermund, 1999). Accordingly, being reminded of a stressor may be less detrimental for older adults as the process of adjusting to the situation may be more important to them than the threat itself. Finally, older adults report passive problem-solving strategies such as avoidance or distancing more often than younger adults do (Folkman et al., 1987; Uchino et al., 2006), and they use strategies more effectively in the sense that a strategy matches a pursued goal (BlanchardFields, 2007). Such a difference may also characterize the tone of older adults' intrusive thoughts. Older adults may have developed ways to distance themselves from threatening thought contents. Moreover, if problems indeed become more manageable, the content of intrusive thoughts should reflect that.

The previous points in favor of a potentially less threatening nature of intrusive thoughts lead to the expectation that the link between negative affect and intrusive thoughts should be reduced in older adults. As intrusive thoughts and negative affect co-occur and interact when people experience stress, a reduced link in older adults is in line with the idea of reduced affective reactivity in older adults. Levels of intrusive thoughts should also be reduced in older adults. Such differences may share predictive variance with age in the moderation of the stress-affect link.

\section{Hypotheses}

This study pursued four aims. First, we wanted to provide additional findings on age differences in affective reactivity to daily stressors (Aim 1). We hypothesized reduced affective reactivity in older adults because this assumption remains the one most substantiated from a theoretical point of view.

Second, we examined age differences in intrusive thoughts (Aim 2). Unless noted, the following assumptions apply to both types of intrusive thoughts (stressor-related INTH, unspecific INTH). In line with the few previous empirical findings, we expected older adults to have reduced levels of intrusive thoughts. We also assumed that intrusive thoughts have state-like qualities (i.e., that their intensity varies across days). Investigating intrusive thoughts as a correlate of daily stressors, we hypothesized an increase of unspecific INTH on stressor days. Guided by cross-sectional findings, we tentatively expected older adults to show a reduced intrusive-thoughts-stressor-coupling.

Third, we investigated how intrusive thoughts are related to negative affect in the two age groups (Aim 3). As described above, the threatening nature of intrusive thoughts may decline with age. Therefore, we hypothesized that the level of experiencing intrusive thoughts is positively associated with the level of negative affect, but that the association is reduced in older as compared to younger adults (between-person differences). Likewise, we hypothesized that a positive day-to-day coupling between intrusive thoughts and negative affect is reduced in older adults (within-person level).

Fourth, we investigated the role of intrusive thoughts for age differences in stress-affect relations (Aim 4). The assumptions that levels of intrusive thoughts and the negative impact of intrusive thoughts on affective well-being may be reduced in older adults guided the following. We examined whether individuals with higher levels of intrusive thoughts have stronger day-to-day couplings between stressors and negative affect. Such a moderation should be reduced in older adults. In addition, we explored 
whether age differences in affective reactivity are partly predicted by differences in average levels of experiencing intrusive thoughts. Finally, we hypothesized a three-way cross-level interaction in which the coupling between events and affect is stronger on days with higher scores of intrusive thoughts (2-way level-1 interaction), but to a lesser extent in older adults (cross-level interaction with age). The last of these suggestions reflects the intertwined nature of different subcomponents characterizing daily stress and age group differences therein. It implies a dynamic, time-varying nature of affective responses to stress, depending on expressions of intrusive thoughts on a particular day.

\section{Conceptual-Methodological Considerations}

We addressed Aim 3 at the between-person level (i.e., do individuals with higher levels of intrusive thoughts have higher levels in negative affect?) and the within-person level (i.e., is a day with more intrusive thoughts a day with more negative affect?). Furthermore, we addressed moderation at different levels of analysis (Aim 4), namely as a cross-level interaction (i.e., do levels of intrusive thoughts impact stress-affect couplings) and at the within-person level (i.e., is the stress-affect coupling larger on days with more intrusive thoughts). The test of associations among variables at different levels of analysis (the between- and withinperson level) is desirable because between-person relations do not have to translate to how variables relate at the within-person level (Molenaar, 2004; Schmitz, 2000). One condition for generalizing across levels of analysis is that the processes generating variability between and within individuals are identical (i.e., variation equivalence; Lindenberger \& von Oertzen, 2006). The hypotheses above imply variation equivalence as we assumed that a day's level of intrusive thoughts has analogous consequences as a person's level (high levels-more negative affect). That is, the mechanisms linking intrusive thoughts to negative affect and stressor occurrence should be alike. By investigating intrusive thoughts at different levels of analyses, their general importance for affective experiences and affect-stress relations can be determined best.

\section{Method}

The current investigation is part of a larger study, the COGITO Study, conducted at the Center for Lifespan Psychology, Max Planck Institute for Human Development, Berlin (Schmiedek, Bauer, Lövdén, Brose, \& Lindenberger, 2010; Schmiedek, Lövdén, \& Lindenberger, 2010). The COGITO Study followed a pretest-posttest control group design with a microlongitudinal phase of 100 days in the experimental group. The present study focused on this phase that took place between July 2006 and February 2008.

\section{Participants and Procedure}

The current study included 101 younger adults (51.5\% women; age $=20-31, M=25.6, S D=2.7)$ and 103 older adults $(49.5 \%$ women; age $=65-80, M=71.3, S D=4.1$ ). For information on marital status, education, and work status, see Table 1. Participants of the COGITO study were recruited through newspaper advertisements, word-of-mouth recommendation, and flyers circulated in Berlin, Germany. Study participation included a pre- and post-
Table 1

Sociodemographic Characteristics of Sample

\begin{tabular}{lcc}
\hline & Younger adults & Older adults \\
\hline Marital status, \% & & \\
Nonmarried & 98 & 9.7 \\
Married & 2 & 49.5 \\
Divorced & - & 22.3 \\
Widowed & - & 18.4 \\
Education, $M$ & 12.5 & \\
Years of high school & 3.6 & 10.8 \\
Years of university & 0.9 & 2.9 \\
Years of training & & \\
Work status, $\%$ & 67 & - \\
University students & 13 & - \\
Employed & 11 & - \\
Unemployed & 8 & 100 \\
Students & 1 & \\
Apprentices & - & \\
Retired & & \\
\hline
\end{tabular}

test (10 days each, 2-2.5 h) and a microlongitudinal phase (about 100 sessions, $1-1.5 \mathrm{~h}$ each). The total number of sessions per person in the microlongitudinal phase ranged from 87 to 107 ( $M=$ 101; differences occurred because of organizational issues), and this phase was completed in 23 weeks (mean number of days $=$ 158 , median number of days $=148$; differences occurred because of individual differences in participation frequency per week).

Attrition occurred during pretest ( 7 younger and 10 older adults) and during the 100 daily sessions (19 younger and 5 older adults). Reasons given for dropping out of the study were illness ( 5 older adults), lack of interest (2 younger and 3 older adults), time and effort necessary for participation (7 younger and 4 older adults), move away from Berlin (5 younger adults), or they were unclear (12 younger and 3 older adults). Three younger adults were excluded from participation because of their unreliability. Incentives for study participation varied between 1450 and 1950 Euros. A bonus system was implemented to reduce attrition and motivate participants to complete the study quickly. The daily sessions were carried out from Monday to Saturday between 8 a.m. and 7.30 p.m. During this phase, participants worked on the tasks individually in rooms with three to six work places. Each assessment included a visual acuity task, followed by computerized self-report (5-8 min), 12 different computerized cognitive tasks (40-65 min), and another self-report (1-2 min). The laboratory was equipped with 32 identical PCs. From the larger battery of self-report variables, this study focused on measures of daily stressors, affect, and intrusive thoughts.

\section{Measures}

Daily stressors. These were assessed by means of a list of categories. The choice of categories was based on the Daily Inventory of Stressful Experiences (Almeida, Wethington, \& Kessler, 2002) and on a review of event questionnaires (Zautra, Affleck, \& Tennen, 1994). Participants were asked whether they had experienced one of the following seven events since the last time they had come to the lab or whether such an event would occur later during that day: Having an argument with someone; 
having a disagreement over something without clarification; some event related to work; to a friend; to health; to leisure; and to finances. We also asked whether so many things that require action or attention co-occurred that it could be called "stress" (overload category). If events occurred, participants were asked to rate their valence (negative, slightly negative, neutral, slightly positive, and positive). Another three categories were not used for analyses in this study: important memories, threatening boredom, and an open category. All negative events were included as a dichotomous variable in the analyses (any stressor did/did not occur) unless a category was reported on more than $90 \%$ of the occasions. In addition, individuals' overall proportion of sessions with at least one stressor was included in some analyses.

Negative affect. To assess daily affect, a 20-item state version of the Positive Negative Affect Schedule (PANAS; Watson, Clark, \& Tellegen, 1988) was applied. In the present study, the 10 -item negative affect subscale was relevant. Subjects rated their momentary mood on an 8-point scale from 0 (does not apply at all) to 7 (applies very well). Five items were excluded from analyses (guilty, scared, hostile, ashamed, afraid) because they showed very low variability across the microlongitudinal phase. Twenty percent of the participants did not fluctuate at all on these items (intraindividual $S D=0$ ). The internal consistency of the remaining items (distressed, jittery, nervous, upset, and irritable) was calculated across subjects on 100 sessions, resulting in an average Cronbach's $\alpha$ of .87 (ranging from .81 to .91 on session 1 to 100 ). The average score across the five items went into the analyses.

Unspecific intrusive thoughts. To measure unspecific INTH, two items were adapted from ${ }^{1}$ the Stress Coping Inventory (SVF 78; Janke \& Erdmann, 2002), a German instrument to measure reactions to stress. Participants were asked to rate how much the statements "Today, I can not get certain thoughts out of my mind" and "Today, I keep thinking about something again and again" matched their thoughts and feelings that day. To capture the self-related component of intrusive thoughts (e.g., Kuhl \& Baumann, 2000), a third item was developed, "Today, I have difficulties suppressing thoughts about myself." Again, an 8-point answering scale was used (see above). The average Cronbach's $\alpha$ of the scale was .89 (ranging from .82 to .92 across occasions).

Stressor-related intrusive thoughts. We also assessed recurring thoughts about events that were reported with the question "How much does the following statement describe how you are dealing with the event?" followed by the item "I am thinking about it over and over again." This was prompted after participants indicated an event occurrence. Answers were given on an 8-point scale (see above).

\section{Statistical Analyses}

To account for the hierarchical structure of the data we addressed research questions in a multilevel modeling framework. The analyses were conducted using SAS PROC MIXED. Two levels were considered, sessions (level-1) and individuals (level-2). Variables such as negative affect that were collected on a daily basis are time-varying, level-1 variables. Characteristics of the participants that are stable (in a conceptual sense) are level-2 variables (e.g., age group). The analyses were carried out with level- 2 predictors centered around the sample mean and with time-varying predictors centered around each person's mean (Singer \& Willet, 2003). We modeled the autoregressive structure of our data with a procedure that took differences in intervals between measurement occasions into consideration (with the SPATIAL POWER covariance function in the REPEATED statement of SAS PROC MIXED). In the models under investigation, variance components corresponding to fixed effects were tested with a likelihood ratio test.

\section{Results}

Results of descriptive analyses are provided in Table 2. For each age group, we report the average percentage of days with events, intraindividual levels and standard deviations of study variables, as well as intraindividual correlations among those variables that were measured on a daily basis. The correlations reported were computed between variables within individuals (i.e., correlation coefficients were derived for single individuals). Note that between-person differences in within-person correlations were considerable as indicated by the standard deviations. These differences need to be kept in mind when inspecting later results that provide information on "average individuals" generated in the multilevel modeling framework. In addition, some correlations were calculated on the basis of few occasions only, limiting their reliability.

\section{Aim 1: Age Differences in Stressor-Affect Couplings}

The following multilevel model was carried out to examine whether affective reactivity to daily stressors was reduced in older as compared to younger adults:

$$
\begin{aligned}
& \mathrm{NA}_{\mathrm{ij}}= \beta_{0}+\beta_{l}\left(\text { Session }_{\mathrm{ij}}\right)+\beta_{2}\left(\text { Age Group }_{\mathrm{j}}\right) \\
&\left.+\beta_{3} \text { Level Stressors }_{\mathrm{j}}\right)+\beta_{4}\left(\text { Daily Stressors }_{\mathrm{ij}}\right) \\
&\left.+\beta_{5} \text { (Daily Stressors }_{\mathrm{ij}} \times \text { Age Group }_{\mathrm{j}}\right)+u_{0 i}+u_{l i}\left(\text { Session }_{\mathrm{ij}}\right) \\
&+u_{2 i}\left(\text { Daily Stressors }_{\mathrm{ij}}\right)+r_{i j} .
\end{aligned}
$$

In this equation, negative affect of person $i$ on occasion $j$ is predicted by an intercept, $\beta_{O}$, the person's age group, $\beta_{2}$, the average level of daily stressors across study days, $\beta_{3}$, and the occurrence of a stressor on day $j, \beta_{4}$. Age group moderates the increase of negative affect on stressor days, $\beta_{5}$. Age group was coded as 0 (younger adults) and 1 (older adults). Person $i$ 's deviation from the average level is denoted by the parameter $u_{O i}$, and the parameter $r_{i j}$ denotes person $i$ 's deviation from this individual level at occasion $j$. Session ${ }_{\mathrm{i} j}$ was included as a level-1 predictor to control in the criterion for trends across study time. The slope parameter, $\beta_{l}$, was allowed to vary across individuals by including the random effect $u_{1 i}$. Random coefficients were assumed to be normally distributed with a mean of zero and variances represented by $\sigma_{u}^{2}$ and $\sigma_{r}^{2}$.

The coupling between daily stressors and negative affect, estimate $=0.46, t(20333)=14.32, p<.001$, was moderated by age group, estimate $=-0.23, t(20333)=-5.09, p<.001($ Table 3,

\footnotetext{
${ }^{1}$ From SVF 78. Eine Kurzform des Stressverarbeitungsfragebogens SVF 120, by W. Janke and G. Erdmann, 2002, Göttingen: Hogrefe. Copyright 2002 by Hogrefe. Adapted with permission. [4th revised edition: SVF Stressverarbeitungsfragebogen, by G. Erdmann and W. Janke, 2008, Göttingen: Hogrefe].
} 
Table 2

Descriptive Statistics: Average Levels, Intraindividual Means and SDs, and Intraindividual Correlations

\begin{tabular}{|c|c|c|c|c|}
\hline & \multicolumn{2}{|c|}{ Younger } & \multicolumn{2}{|c|}{ Older } \\
\hline & $M$ & $S D$ & $M$ & $S D$ \\
\hline Days with stressors & 37 & 26 & 25 & 24 \\
\hline \multicolumn{5}{|l|}{ Intraindividual means } \\
\hline Negative affect" & 1.32 & 0.93 & 0.49 & 0.74 \\
\hline Unspecific intrusive thoughts* & 2.89 & 1.34 & 1.71 & 1.37 \\
\hline Stressor-related intrusive thoughts* & 3.86 & 1.29 & 2.49 & 1.47 \\
\hline \multicolumn{5}{|l|}{ Intraindividual $S D \mathrm{~s}$} \\
\hline Negative affect & 0.76 & 0.34 & 0.34 & 0.28 \\
\hline Unspecific intrusive thoughts & 1.10 & 0.44 & 0.77 & 0.39 \\
\hline Stressor-related intrusive thoughts & 1.34 & 0.44 & 1.13 & .54 \\
\hline \multicolumn{5}{|l|}{ Intraindividual correlations } \\
\hline$r_{\text {stressors, negative affect }} \mathrm{a}$ & .26 & .15 & .19 & .18 \\
\hline$r_{\text {stressors, unspecific intrusive thoughts }} \mathrm{b}$ & .20 & .16 & .17 & .17 \\
\hline$r_{\text {negative affect, unspecific intrusive thoughts }}{ }^{\mathrm{c}}$ & .40 & .19 & .21 & .21 \\
\hline
\end{tabular}

${ }^{*}$ Age group comparisons revealed difference, $p<.05$. Correlation could not be calculated ${ }^{\text {a }}$ for 2 younger and 10 older adults, ${ }^{\mathrm{b}}$ for 2 younger and 2 older adults, and ${ }^{\mathrm{c}}$ for 7 older adults because no stressors were reported or because of low variance in negative affect.

Model 1). Age group explained $19 \%$ of the slope variation. The negative interaction indicates a reduced coupling in older adults. Thus, days with stressors were days with increased negative affect, but older adults' stressor-affect association was lower than younger adults'. This finding is in accordance with this study's hypotheses.

\section{Aim 2: Intrusive Thoughts: Age Differences in Level, Variation, and Couplings With Stress}

In the following, intrusive thoughts refers to both types of intrusive thoughts (stressor-related INTH, unspecific INTH). The hypothesis tested next was that older adults had reduced average levels of both (a) unspecific INTH and (b) stressor-related INTH. That is, do the levels presented in Table 2 statistically differ? This was tested with the following composite model, with parameters analogous to those described in Equation (1)

$$
\begin{aligned}
\text { INTH }_{\mathrm{ij}}=\beta_{0}+\beta_{l}\left(\text { Session }_{\mathrm{ij}}\right)+\beta_{2} & \left(\text { Age } \operatorname{Group}_{\mathrm{j}}\right)+u_{0 i} \\
& +u_{l i}\left(\text { Session }_{\mathrm{ij}}\right)+r_{i j} .
\end{aligned}
$$

As expected, older adults had lower average levels of (a) unspecific INTH, estimate $=-1.18, t(201)=-6.19, p<.001$, and lower average levels of (b) stressor-related INTH on stressor days, estimate $=-1.39, t(193)=-7.27, p<.001$, than younger adults. Age group explained $15 \%$ of intercept variance in unspecific INTH and $23 \%$ of intercept variance in stressor-related INTH.

Was there variation in the amount of intrusive thoughts experienced across days? According to the intraindividual SD (Table 2),

Table 3

Intraindividual Couplings Between Daily Stressors and Negative Affect and Unspecific Intrusive Thoughts, Respectively, in the Two Age Groups

\begin{tabular}{lcc}
\hline & Model 1: Criterion-negative affect & Model 2: Criterion-intrusive thoughts \\
\hline Fixed effects $(S E)$ & & \\
Intercept & $1.14^{*}(0.08)$ & $2.62^{*}(0.13)$ \\
Age group & $-0.62^{*}(0.12)$ & $-0.98^{*}(0.18)$ \\
Level stressors & $0.95^{*}(0.23)$ & $1.52^{*}(0.36)$ \\
Daily stressors & $0.46^{*}(0.03)$ & $0.51^{*}(0.05)$ \\
Daily stressors $\times$ Age group & $-0.23^{*}(0.05)$ & $-0.04(0.07)$ \\
Variance components & 0.67 & 1.62 \\
Intercept & $0.08^{\mathrm{a}}$ & $0.14^{\mathrm{a}}$ \\
Slope (daily stressors) & 0.36 & 0.90 \\
Residual variance & $9 \%$ & $6 \%$ \\
Pseudo- $R^{2}$ & & $6 \%$ \\
Within-person variation & $9 \%$ & \\
\hline
\end{tabular}

Note. Level stressors is the proportion of study days with at least one stressor; change in criterion variable across study time was controlled for, but is not reported; the Pseudo- $R^{2}$ statistic was derived by a comparison with the residual variance from the unconditional change model that controlled for change in the criterion.

${ }^{a}$ Model improved significantly according to $-2 \mathrm{LL}$ statistic when variance component was estimated.

* $p<.05$. 
younger and older adults varied (a) across study days regarding unspecific INTH and (b) across days with stressors regarding stressor-related INTH. The intraclass correlation, $\rho$, calculated as $\rho=\sigma_{u}^{2} /\left(\sigma_{r}^{2}+\sigma_{u}^{2}\right)$, provided additional information on how much the variation in intrusive thoughts within individuals across time contributed to the total variance observed in intrusive thoughts. The variance components $\sigma_{r}^{2}$ and $\sigma_{u}^{2}$ were derived by fitting an unconditional multilevel model for both age groups (Singer \& Willett, 2003). In both age groups and for both types of intrusive thoughts, the relative amount of day-to-day variation accounted for at least $28 \%$ of the total variation (Figure 1). Thus, intrusive thoughts had state-like and trait-like qualities in both age groups.

We predicted that days with stressors would be days with more intrusive thoughts, but less so in older adults. A model analogous to Equation (1) was tested but predicting unspecific INTH. Results (Table 3, Model 2) indeed showed a positive coupling between daily stressors and unspecific INTH, estimate $=0.51, t(20333)=$ $11.22, p<.001$, with intrusive thoughts explaining $6 \%$ of residual (within-person) variance, but no age group differences, estimate $=$ $-0.04, t(20333)=-0.54, p>.05$. Thus, counter to our expectation, both age groups showed a comparable increase in unspecific INTH when stressors occurred.

\section{Aim 3: Age Differences in Relations of Negative Affect and Intrusive Thoughts (Between- and Within-Person Level)}

Next, we addressed the question how intrusive thoughts were related to negative affect in younger and older adults. Regarding between-person differences, we hypothesized that the more intrusive thoughts individuals experience on average, the higher their levels of negative affect would be, and that this relation would be reduced in older adults. The hypothesis was tested using the equation

$$
\begin{aligned}
& \text { NA }_{\mathrm{ij}}=\beta_{0}+\beta_{l}\left(\text { Session }_{\mathrm{ij}}\right)+ \beta_{2}\left(\text { Age Group }_{\mathrm{j}}\right) \\
&+\beta_{3}\left(\text { Level INTH }_{\mathrm{j}}\right)+\beta_{4}\left(\text { Level INTH }_{\mathrm{j}} \times \text { Age Group }_{\mathrm{j}}\right) \\
&+u_{0 i}+u_{l i}\left(\text { Session }_{\mathrm{ij}}\right)+r_{i j} .
\end{aligned}
$$

Besides age group, predictors of the level of negative affect are the average level of intrusive thoughts across study days, $\beta_{3}$, as well as an interaction between this level and age group, $\beta_{4}$.
Individuals with higher levels of (a) unspecific INTH indeed had higher levels of negative affect across study days, estimate $=0.38$, $t(199)=7.18, p<.001$, and this relation was moderated by age group, estimate $=-0.16, t(199)=-2.15, p=.03$ (Table 4 , Model 1; Figure 2). The same was true for days with events as another test revealed. Average levels of negative affect on stressor days were predicted by average levels of (b) stressor-related INTH, estimate $=0.33, t(191)=4.72, p<.001$. Again, this betweenperson difference was moderated by age group, estimate $=-0.20$, $t(191)=-2.12, p=.04$. Both results support the notion that experiencing intrusive thoughts in general or as a response to stressors is associated with lower well-being. Relative to younger adults, this association was dampened among older adults.

We then investigated the relations between affect and intrusive thoughts at the within-person level. Are (a) days with high scores of unspecific INTH and (b) stressor-days with high scores of stressor-related INTH characterized by above-average negative affect? The model tested is comparable to Equation (1), with age group and level of intrusive thoughts as between-person (level-2) predictors, daily intrusive thoughts as the time-varying predictor (level-1), and an interaction term "daily INTH $\times$ age group" testing age group differences. The findings supported the hypothesis (Table 4, Model 2; Figure 3). On days with (a) more-thanaverage unspecific INTH, individuals had higher expressions of negative affect, estimate $=0.28, t(20333)=18.36, p<.001$, and this within-person coupling was smaller in older adults, estimate $=$ $-0.16, t(20333)=-7.38, p<.001$. Age group explained $26 \%$ of the slope variance. Likewise, when (b) only analyzing stressor days, days with more stressor-related INTH were days with more negative affect, estimate $=0.18, t(6059)=11.49, p<.001$, and this association was reduced in older adults, estimate $=-0.09$, $t(6059)=-3.48, p=.001$, with the slope variance explained by age group being $13 \%$. These results are in line with the idea that experiencing intrusive thoughts is accompanied by diminished mood and vice versa. And again, the association strength was smaller for older adults.

\section{Aim 4: Age Group Differences in Effects of Intrusive Thoughts on Stressor-Affect Couplings}

We now turn to the role of intrusive thoughts for stressor-affect couplings in younger and older adults. Do individuals with higher

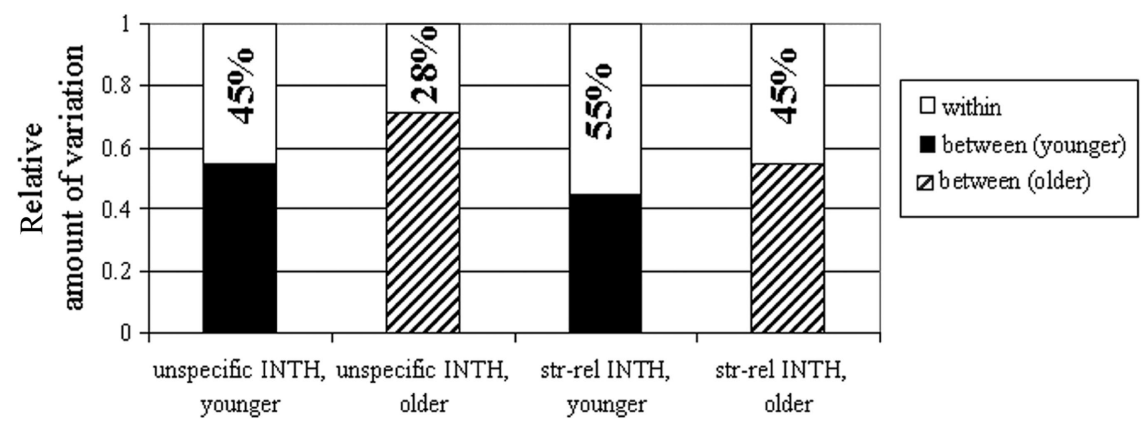

Figure 1. Total amount of variation of unspecific intrusive thoughts (unspecific INTH) and stressor-related intrusive thoughts (str-rel INTH) decomposed into variation within individuals across days and variation between individuals. 
Table 4

The Role of Intrusive Thoughts (INTH) for Negative Affect in Younger and Older Adults (Between-Person and Within-Person Level)

\begin{tabular}{|c|c|c|c|c|}
\hline & \multicolumn{4}{|c|}{ Criterion variable in all models: Negative affect } \\
\hline & \multicolumn{2}{|c|}{ Model 1 (between-person) } & \multicolumn{2}{|c|}{ Model 2 (within-person) } \\
\hline & A: Unspecific INTH & B: Stressor-related INTH & A: Unspecific INTH & B: Stressor-related INTH \\
\hline \multicolumn{5}{|l|}{ Fixed effects $(S E)$} \\
\hline Intercept & $1.00^{*}(0.08)$ & $1.43^{*}(0.10)$ & $1.05^{*}(0.08)$ & $1.43^{*}(0.10)$ \\
\hline Age group & $-0.40 *(0.11)$ & $-0.64 *(0.15)$ & $-0.45^{*}(0.11)$ & $-0.65^{*}(0.14)$ \\
\hline Level INTH (A or B) & $0.38^{*}(0.05)$ & $0.33^{*}(0.07)$ & $0.35^{*}(0.05)$ & $0.33^{*}(0.07)$ \\
\hline Level INTH $\times$ age group & $-0.16^{*}(0.07)$ & $-0.20 *(0.10)$ & $-0.16^{*}(0.07)$ & $-0.20^{*}(0.09)$ \\
\hline Daily INTH (A or B) & & & $0.28^{*}(0.02)$ & $0.18^{*}(0.02)$ \\
\hline Daily INTH $\times$ age group & & & $-0.16^{*}(0.02)$ & $-0.09^{*}(0.03)$ \\
\hline \multicolumn{5}{|l|}{ Variance components } \\
\hline Intercept & 0.57 & 0.72 & 0.656 & 0.73 \\
\hline Slope (daily INTH, A or B) & 0.34 & 0.72 & $0.02^{\mathrm{a}}$ & $0.01^{\mathrm{a}}$ \\
\hline Residual variance & & & 0.32 & 0.64 \\
\hline \multicolumn{5}{|l|}{ Pseudo- $R^{2}$} \\
\hline Within-person variation & & & $25 \%$ & $12 \%$ \\
\hline
\end{tabular}

Note. Model A: Change in criterion variable across study time was controlled for but is not reported. The Pseudo- $R^{2}$ statistic was derived by a comparison with the residual variance from the unconditional change model that controlled for change in the criterion (Model A) and the unconditional means model (Model B).

${ }^{a}$ Model improved significantly according to the $-2 \mathrm{LL}$ statistic when variance in fixed effect was estimated.

$* p<.05$.

levels of intrusive thoughts have stronger stress-affect couplings, and is this moderation reduced in older adults? The following model was tested

$$
\begin{aligned}
& \text { NA }_{\mathrm{ij}}= \beta_{0}+\beta_{l}\left(\text { Session }_{\mathrm{ij}}\right)+\beta_{2}\left(\text { Age Group }_{\mathrm{j}}\right) \\
&+ \beta_{3}\left(\text { Level Stressors }_{\mathrm{j}}\right)+\beta_{4}\left(\text { Level INTH }_{\mathrm{j}}\right) \\
&+\beta_{5}\left(\text { Age }_{\text {Group }} \times \text { Level INTH }_{\mathrm{j}}\right)+\beta_{6}\left(\text { Daily Stressors }_{\mathrm{ij}}\right) \\
&+\beta_{7}\left(\text { Daily Stressors }_{\mathrm{ij}} \times \text { Age Group }_{\mathrm{j}}\right) \\
&+\beta_{8}\left(\text { Daily Stressors }_{\mathrm{ij}} \times \text { Level INTH }_{\mathrm{j}}\right)
\end{aligned}
$$

$$
\begin{gathered}
+\beta_{9}\left(\text { Daily Stressors }_{\mathrm{ij}} \times \text { Level INTH }_{\mathrm{j}} \times \text { Age Group }_{\mathrm{j}}\right)+u_{0 i} \\
+u_{l i}\left(\text { Session }_{\mathrm{ij}}\right)+u_{2 i}\left(\text { Daily Stressors }_{\mathrm{ij}}\right)+r_{i j} .
\end{gathered}
$$

In this model, age group, level stressors, and level INTH are between-person predictors; daily stressors is a within-person predictor. The terms "daily stressors $\times$ level INTH" (2-level two-way interaction) and "daily stressors $\times$ level INTH $\times$ age group" (2-level three-way interaction) are the interaction terms relevant for testing the moderation hypothesis. The parameter testing whether the level of unspecific INTH strengthened the coupling between stress and affect was not significant (Table 5, Model 1 A),
(A) All study days: Level of negative affect

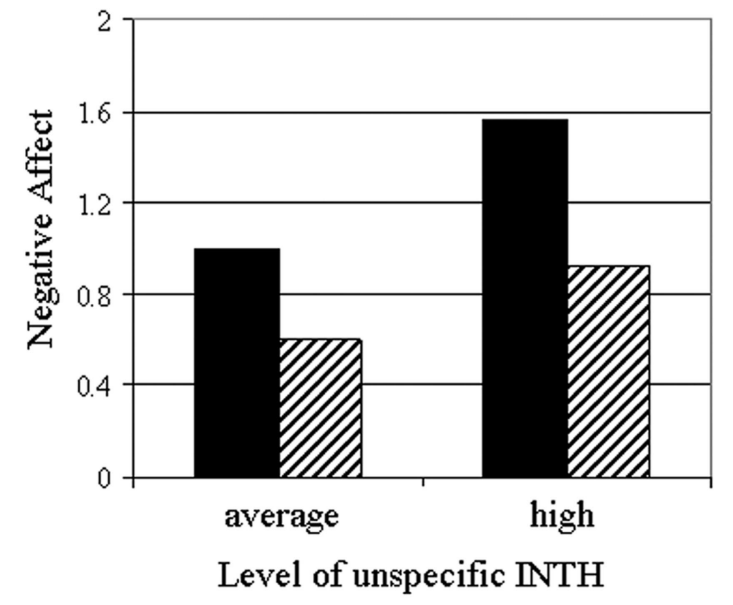

(B) Days with events: Level of negative affect

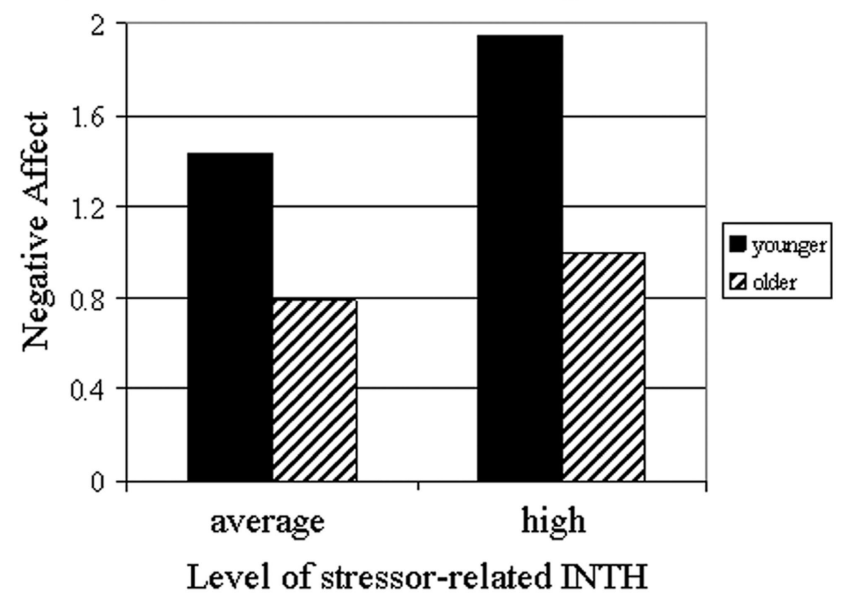

Figure 2. Levels of negative affect as a function of level of intrusive thoughts, age group, and the intrusive thoughts $\times$ age group interaction, separately for (A) all study days and (B) days with stressors; intrusive thoughts (INTH) in (A) are unspecific and in (B) are stressor-related; high denotes $+1 S D$. 
(A) All study days: Within-person coupling negative affect - intrusive thoughts

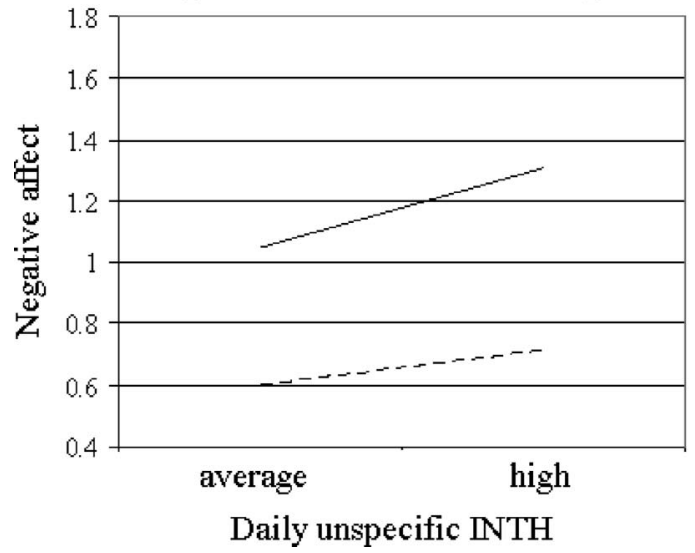

(B) Days with stressors: Within-person coupling negative affect - intrusive thoughts

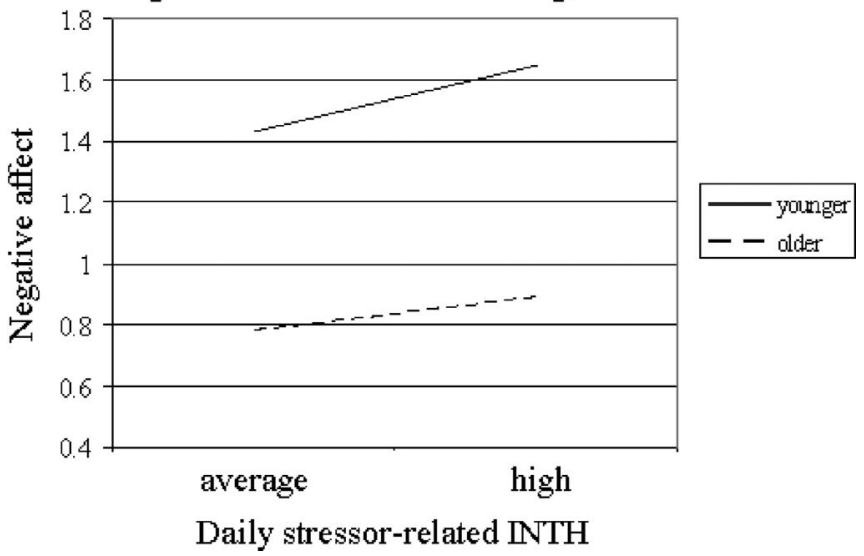

Figure 3. Daily coupling of negative affect and intrusive thoughts (INTH) in both age groups, separately for (A) all study days and (B) days with stressors; INTH in (A) are unspecific and in (B) are stressor-related; high denotes +1 average intraindividual $S D$.

estimate $=0.03, t(20332)=0.96, p>.05$, neither was the analogous parameter for stressor-related INTH, estimate $=0.04, t(20332)=$ $1.43, p>.05$ (Model 1 B). Follow-up analyses that tested the moderating role of the level of intrusive thoughts for affective reactivity separately for the two age groups revealed that the level of unspecific INTH moderated stress-affect couplings, but only in older adults, estimate $=0.06, t(10210)=3.32, p=.001$, and not in younger adults, estimate $=0.02, t(10123)=0.72, p>.05$.

We furthermore explored whether age group differences in affective reactivity can be partly predicted by age group differences in levels of intrusive thoughts. The above analysis was therefore repeated with the additional 2-level predictor "age group $\times$ daily INTH," but without the non-significant 3-way interaction term. Indeed, age group and level of unspecific INTH share predicted variance in affective reactivity to daily stressors (Table 5, Model 2). The parameter representing reduced affective reactivity in older adults (cf. Table 3 , estimate $=-0.23$ ) was smaller when both age group and level of unspecific INTH were simultaneously tested as moderators of within-person stress-affect couplings. When tested separately, age explained $19 \%$ of slope variance (stressors-affect coupling), and the level of unspecific INTH explained $12 \%$. When modeled simultaneously, only $22 \%$ of slope variance was explained, thus, less than an additive amount. Taken together, evidence on the role of the level of intrusive thoughts for stress-affect couplings is limited. Only in older adults does it explain some interindividual differences in reactivity to stress. In addition, age group differences in reactivity are partly predicted by interindividual differences in level of unspecific INTH.

The last hypothesis proposed that the coupling between stressors and affect is larger on days when individuals have high levels of intrusive thoughts, but less so in older adults. This hypothesis implies intraindividual variation of affective reactivity and aims to explain some of this variation with time-varying intrusive thoughts. The composite model under investigation was:

$\mathrm{NA}_{\mathrm{ij}}=\beta_{0}+\beta_{l}\left(\operatorname{Session}_{\mathrm{ij}}\right)+\beta_{2}\left(\right.$ Age Group $\left._{\mathrm{j}}\right)$

$$
\begin{gathered}
+\beta_{3}\left(\text { Level Stressors }_{\mathrm{j}}\right)+\beta_{4}\left(\text { Level INTH }_{\mathrm{j}}\right) \\
+\beta_{5}\left(\text { Daily Stressors }_{\mathrm{ij}}\right)+\beta_{6}\left(\text { Daily Stressors }_{\mathrm{ij}} \times \text { Age Group }_{\mathrm{j}}\right) \\
+\beta_{7}\left(\text { Daily INTH }_{\mathrm{ij}}\right)+\beta_{8}\left(\text { Daily INTH }_{\mathrm{ij}} \times \text { Age Group }_{\mathrm{j}}\right) \\
+\beta_{9}\left(\text { Daily INTH }_{\mathrm{ij}} \times \text { Daily Stressors }_{\mathrm{ij}}\right) \\
+\beta_{10}\left(\text { Daily INTH }_{\mathrm{ij}} \times \text { Daily Stressors }_{\mathrm{ij}} \times \text { Age Group }_{\mathrm{j}}\right) \\
+u_{0 i}+u_{l i}\left(\text { Session }_{\mathrm{ij}}\right)+u_{2 i}\left(\text { Daily Stressors }_{\mathrm{ij}}\right) \\
+u_{3 i}\left(\text { Daily INTH }_{\mathrm{ij}}\right)+u_{4 i}\left(\text { Daily INTH }_{\mathrm{ij}} \times \text { Daily Stressors }_{\mathrm{ij}}\right) \\
+r_{i j} .
\end{gathered}
$$

Time-varying intrusive thoughts and daily stressors were included in the model simultaneously, $\beta_{5}$ and $\beta_{7}$. Both parameters varied across individuals, $u_{2 i}$ and $u_{3 i}$. Furthermore, the interaction of intrusive thoughts and daily stressors was included as a timevarying predictor of negative affect, $\beta_{9}$, implying that the increase in negative affect on stressor days is moderated by the daily score of intrusive thoughts. This level-1 interaction was allowed to vary across individuals, $u_{4 i}$. Finally, a three-way cross-level interaction (level-1, level-1, level-2), $\beta_{10}$, between intrusive thoughts, daily stressors, and age group was examined.

The results generally supported expectations (Table 5, Model 3; cf. Figure 4). The impairment of affective well-being on stressor days was stronger when (a) individuals experienced unspecific INTH on that day that exceeded their average levels, estimate $=$ $0.11, t(20329)=6.1, p<.001$, and when (b) individuals experienced above-average stressor-related INTH, estimate $=0.09$, $t(20329)=5.42, p<.05$. Only the within-person moderation by stressor-related INTH was smaller in older adults, estimate = $-0.05, t(20329)=-2.18, p=.03$. Age group explained $19 \%$ of the slope variance. The within-person moderation by unspecific INTH did not differ across age groups, estimate $=-0.04$, $t(20329)=-1.29, p>.05$. Thus, a disturbance of mood associated with stressor occurrence was further strengthened when indi- 
Table 5

The Role of Intrusive Thoughts (INTH) for Stress-Affect Couplings (Between-Person and Within-Person Moderation)

\begin{tabular}{|c|c|c|c|c|c|c|}
\hline & \multicolumn{6}{|c|}{ Criterion variable in all models: Negative affect } \\
\hline & \multicolumn{2}{|c|}{ Model 1} & \multicolumn{2}{|c|}{ Model 2} & \multicolumn{2}{|c|}{ Model 3} \\
\hline & $\begin{array}{l}\text { A: Unspecific } \\
\text { INTH }\end{array}$ & $\begin{array}{l}\text { B: Stressor- } \\
\text { related INTH }\end{array}$ & $\begin{array}{l}\text { A: Unspecific } \\
\text { INTH }\end{array}$ & $\begin{array}{l}\text { B: Stressor- } \\
\text { related INTH }\end{array}$ & $\begin{array}{l}\text { A: Unspecific } \\
\text { INTH }\end{array}$ & $\begin{array}{l}\text { B: Stressor- } \\
\text { related INTH }\end{array}$ \\
\hline \multicolumn{7}{|l|}{ Fixed effects $(S E)$} \\
\hline Intercept & $0.98 *(0.08)$ & $1.11^{*}(0.08)$ & $1.02 *(0.08)$ & $1.12 *(0.08)$ & $1.07^{*}(0.08)$ & $1.11^{*}(0.09)$ \\
\hline Age group & $-0.39^{*}(0.11)$ & $-0.64^{*}(0.11)$ & $-0.38^{*}(0.11)$ & $-0.60 *(0.11)$ & $-0.44^{*}(0.11)$ & $-0.59^{*}(0.11)$ \\
\hline Level stressors & $0.52 *(0.21)$ & $0.26(0.27)$ & $0.51^{*}(0.20)$ & $0.56^{*}(0.27)$ & $0.18(0.20)$ & $0.28(0.28)$ \\
\hline Level INTH (A or B) & $0.36 *(0.05)$ & $0.32 *(0.07)$ & $0.27 *(0.04)$ & $0.14^{*}(0.05)$ & $0.25 *(0.04)$ & $0.14 *(0.05)$ \\
\hline Level INTH $\times$ age group & $-0.16^{*}(0.07)$ & $-0.31^{*}(0.08)$ & & & & \\
\hline Daily stressors & $0.45^{*}(0.04)$ & $0.45^{*}(0.03)$ & $0.44^{*}(0.03)$ & $0.45^{*}(0.03)$ & $0.33^{*}(0.03)$ & $0.02(0.05)$ \\
\hline Daily stressors $\times$ age group & $-0.20^{*}(0.05)$ & $-0.23^{*}(0.05)$ & $-0.19^{*}(0.05)$ & $-0.23^{*}(0.05)$ & $-0.19^{*}(0.04)$ & $0.06(0.06)$ \\
\hline Daily stressors × level INTH & $0.03(0.02)$ & $0.04(0.03)$ & $0.04 *(0.02)$ & $0.03(0.02)$ & & \\
\hline $\begin{array}{l}\text { Daily stressors } \times \text { level INTH } \times \\
\text { age group }\end{array}$ & $0.03(0.04)$ & $-0.01(0.04)$ & & & & \\
\hline Daily INTH (A or B) & & & & & $0.24^{*}(0.01)$ & $0.11^{*}(0.02)$ \\
\hline Daily INTH $\times$ age group & & & & & $-0.15(0.02)$ & $-0.06^{*}(0.02)$ \\
\hline Daily INTH $\times$ daily stressors & & & & & $0.11^{*}(0.02)$ & $0.09^{*}(0.02)$ \\
\hline Daily INTH $\times$ daily stressors $x$ & & & & & & \\
\hline age group & & & & & $-0.04(0.03)$ & $-0.05^{*}(0.02)$ \\
\hline \multicolumn{7}{|l|}{ Variance components } \\
\hline Intercept & 0.57 & 0.64 & 0.57 & 0.65 & 0.56 & 0.64 \\
\hline Slope (daily stressors) & $0.08^{\mathrm{a}}$ & $0.08^{\mathrm{a}}$ & $0.08^{\mathrm{a}}$ & $0.08^{\mathrm{a}}$ & $0.04^{\mathrm{a}}$ & $0.08^{\mathrm{a}}$ \\
\hline Slope (daily INTH) & 0.36 & 0.36 & 0.36 & 0.36 & $0.01^{\mathrm{a}}$ & $0.01^{\mathrm{a}}$ \\
\hline $\begin{array}{l}\text { Slope (daily INTH } \times \text { daily } \\
\text { stressors) }\end{array}$ & & & & & $0.02^{\mathrm{a}}$ & $0.004^{\mathrm{a}}$ \\
\hline Residual variance & & & & & 0.30 & 0.34 \\
\hline \multicolumn{7}{|l|}{ Pseudo- $R^{2}$} \\
\hline Within-person variation & $9 \%$ & $9 \%$ & $9 \%$ & $9 \%$ & $25 \%$ & $15 \%$ \\
\hline
\end{tabular}

Note. Change in criterion variable across study time was controlled for but is not reported. The Pseudo- $R^{2}$ statistic was derived by a comparison with the residual variance from the unconditional change model that controlled for change in the criterion.

${ }^{\text {a }}$ Model improved significantly according to $-2 \mathrm{LL}$ statistic when variance in fixed effect was estimated.

$* p<.05$.

viduals had high scores of intrusive thoughts on such days. However, the within-person relation between stressors and affect was less affected by stressor-related INTH in older adults.

\section{Discussion}

The results of this study were the following. First, the coupling of daily stressors and negative affect was reduced in older as compared to younger adults. Second, older adults had lower mean levels of intrusive thoughts across 100 days. Third, intrusive thoughts possessed state-like qualities in both age groups, and, fourth, the variation of unspecific INTH was related to stressor occurrence, with comparable strength in both age groups. Fifth, experiencing more intrusive thoughts was associated with higher expressions of negative affect, and this association held at the between-person level (level of intrusive thoughts - level of negative affect) and at the within-person level (daily intrusive thoughts - daily negative affect). Both associations were smaller in older adults. Sixth, higher levels of unspecific INTH were associated with stronger affective reactivity in older adults and interindividual differences in this level partly predicted age differences in affective reactivity. Finally, days with high expressions of intrusive thoughts were characterized by a stronger coupling between stressors and affect. Regarding stressor-related INTH, the withinperson moderation was reduced in older adults.

\section{Correlates of Daily Stressors: Negative Affect and Intrusive Thoughts}

Older adults' affective reactivity to daily stressors was smaller than younger adults'. This finding is consistent with other studies on affective reactivity (e.g., Uchino et al., 2006), with theories suggesting better emotion regulation in older adulthood (Carstensen et al., 2003), and with the suggestion of habituation to contextual influences with increasing age (Lawton et al., 1996). Older adults have been shown to express similar intensity of emotions to younger adults once they were elicited, but also to be faster in up-regulating in reaction to emotional disturbances (Carstensen et al., 2000), the latter being in line with findings showing that older adults are more successful in their problemsolving strategies (Blanchard-Fields, 2007). Because in our study assessments took place on a day-to-day basis, which may not be frequent enough to capture stressors and responses in close proximity, it cannot be ruled out that the initial response to the stressors was age-invariant, but that older adults already were further along the way in a regulation process when they were measured than 
(A) Coupling of negative affect, stressors, and unspecific intrusive thoughts

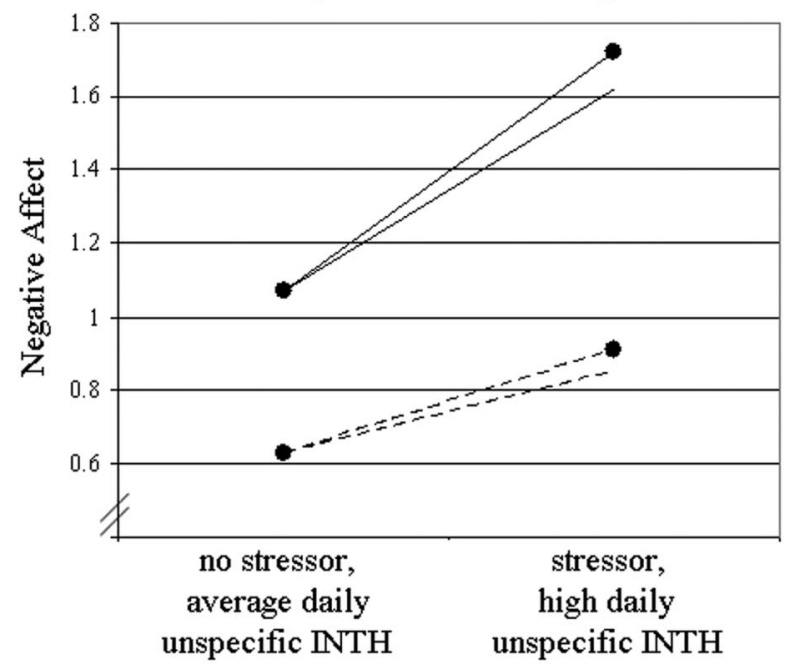

(B) Coupling of negative affect, stressors, and stressor-related intrusive thoughts

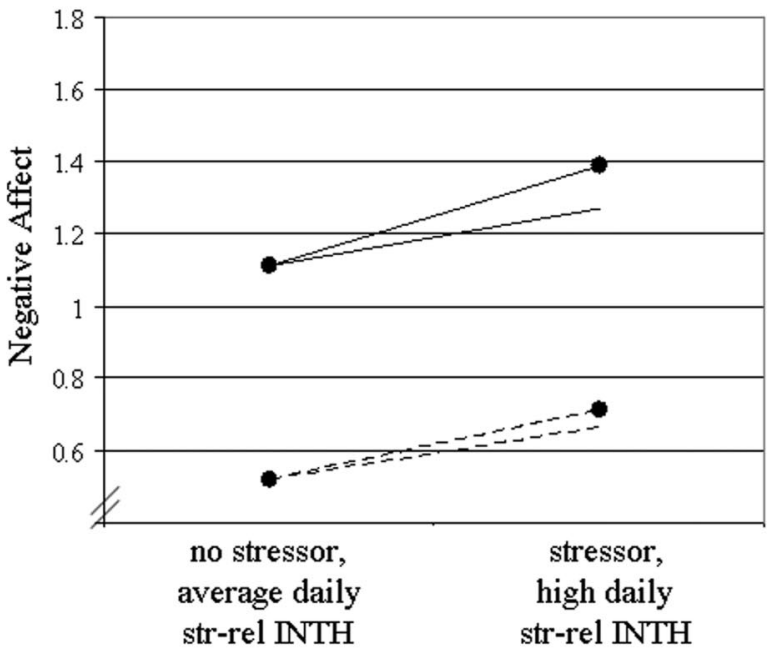

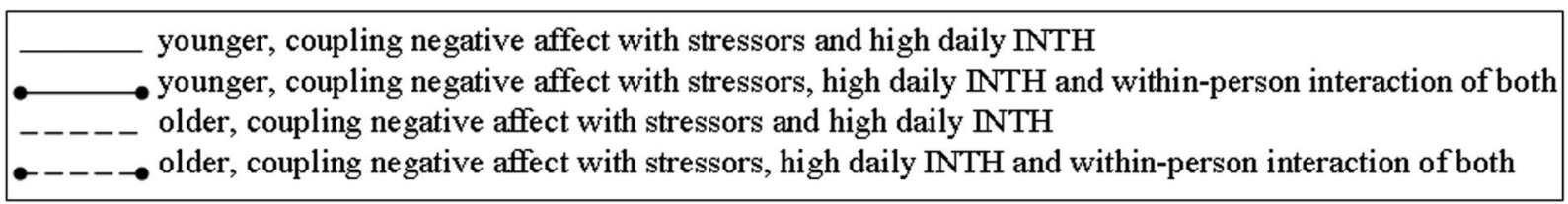

Figure 4. Daily coupling of negative affect, intrusive thoughts (INTH) and daily stressors in both age groups, as well as a within-person moderation of the stressor-affect relation by INTH; INTH in (A) are unspecific and in (B) are stressor-related (str-rel); high denotes +1 average intraindividual $S D$.

younger adults, resulting in reduced couplings and indicating better emotion regulation.

This interpretation is not consistent with findings from some other studies also assessing stressor-affect couplings on a daily basis. Those studies observed equal (Stawski et al., 2008) or increased reactivity in older adults (Mroczek \& Almeida, 2004). A feature that distinguishes our study from Stawski and colleagues' investigation (2008) is the average age of the older group, which was higher in the Stawski et al. (2008) study (mean age $=80$ years). Events faced by adults of this age may have been more harmful than the ones reported in our study, or coping resources may have strongly declined by that age (Sliwinski et al., 2009). Another explanation for our findings may be related to culture and cohort. In another study that was similar in design to ours and also conducted in Germany, results point in the same direction (Röcke et al., 2009). One may speculate that the generation of older adults who participated in our study and who were born between 1926 and 1941, may be more immune to today's daily hassles because they grew up during a period in which many people were suffering from war and poverty.

On days with daily stressors we also found increases in intrusive thoughts. This supports our consideration of intrusive thoughts as one correlate of daily stress, replicates previous findings on cognitive reactivity to daily stressors (Moogle et al., 2008; Nezlek, 2005), and provides a direct comparison of younger and older adults. As the intrusive-thoughts items in this study were not confounded with negative affect, an increase in intrusive thoughts on stressor days may indicate appraisal that is not necessarily negative in content (Lazarus \& Folkman, 1984). An increase of intrusive thoughts could also reflect participants' dwelling on threatening aspects of an event or an increase of general worries on stressor days. As intrusive thoughts strengthened the association between daily stressors and negative affect (see below), it seems plausible that their content was of negative valence.

Cross-sectional findings on reduced levels of intrusive thoughts in older adults (Erskine et al., 2007) guided our hypothesis that an increase in intrusive thoughts on stressor days would be more pronounced in younger adults. It is interesting to note that this was not the case, even though we found reduced levels of unspecific and stressor-related INTH in older adults. This suggests that cognitive reactivity as measured at the intraindividual level is comparable across age groups and that the function of this basic correlate of daily stressors is well preserved across the lifespan.

\section{Negative Affect and Stress-Affect Couplings: The Role of Intrusive Thoughts}

As expected, intrusive thoughts were less tightly linked to negative affect in older than in younger adults. At the betweenperson level, higher levels of negative affect were found (a) across all study days in those individuals with higher levels of unspecific INTH and (b) on days with stressors, in those with higher levels of stressor-related INTH. At the within-person level, (a) days with above-average negative affect were days characterized by high levels of unspecific INTH, and (b) on stressor days, negative affect 
was higher the more stressor-related INTH individuals had. All of these associations were dampened in older adults.

A number of changes across adulthood may contribute to this finding. The content of intrusive thoughts may change with age (e.g., focus on relatively more positive aspects of an issue in older adults), in accordance with some evidence identifying reappraisal as the preferred form of emotion regulation in older adulthood (John \& Gross, 2004). Older adults may also avoid reflecting on negative affective experiences which is described as one mechanism by which intrusive thoughts prolong negative states (NolenHoeksema et al.,1993). Thereby, a downward spiral of affect in the face of intrusive thoughts, or a reciprocal interaction between intrusive thoughts and negative affect (Moberly \& Watkins, 2008), would be buffered in older adults. These speculations should be followed up in future studies. A broader implication of these findings is that intrusive thoughts possibly play an explanatory role regarding the stability of well-being in old age that has sometimes been described as a paradox in the face of age-graded losses (e.g., in health, Kunzmann, Little, \& Smith, 2000). In the face of such losses, a reduced link between negative affect and intrusive thoughts may be beneficial for well-being in older adults.

We also expected a link between intrusive thoughts and negative affect in relation to daily stressors and that this link would be reduced in older adults. Indeed, a particular day's score of intrusive thoughts clearly mattered for affective reactivity. An increase in negative affect on stressor days was higher on days with above-average daily expressions of (a) unspecific INTH and of (b) stressor-related INTH. Regarding the latter, the within-person moderation of the stress-affect coupling by intrusive thoughts was smaller in older adults. The latter finding provides further evidence that experiencing intrusive thoughts is more independent of negative affect in older adults. In line with the reasoning above, when having stressor-related INTH, older adults may be less likely to direct their intrusive thoughts to the threatening features of an event. Such changes would be in line with the claim that affect regulation improves from early to late adulthood (Charles \& Carstensen, 2007), and that it also does so in daily life when individuals are faced with minor daily hassles — an issue that is still debated (e.g., Sliwinski et al, 2009). A reduced interaction of stressor-related INTH with affective reactivity in older adults may be a global indicator of coping being appraised as more effective, of an ability to distance oneself from emotions associated with an event, or of a tendency to accept and adapt to events - thus, an indicator reflecting potential improvements associated with aging (e.g., Blanchard-Fields, 2007).

But why is the moderating role of unspecific INTH not reduced in older adults? This question is intriguing because older adults had lower levels of both types of intrusive thoughts and lower associations between them and negative affect. One interpretation is that on days with stressors, unspecific INTH represent an appraisal of the stressor in relation to the self, for example the feeling of uncontrollability (Rachman, 1981). Given our findings, the impact of such feelings would operate similarly in the two age groups, independently of the average level and other than stressorrelated thoughts that are less detrimental for older adults.

The role of the level of intrusive thoughts in stress-affect couplings was also explored and was shown to be of some importance. The level of unspecific INTH moderated how strongly individuals reacted to stress, but only in older adults. In addition, some of the age differences in affective reactivity can be predicted by individual differences in levels of unspecific INTH. The reduced level of unspecific INTH in older adults may play a role in explaining their reduced affective reactivity.

In sum, our findings are in line with the suggestion that experiencing recurring thoughts enhance periods of high negative affect that can be found in various accounts of intrusive thoughts or related constructs (Lyubomirsky et al., 2003; Nolen-Hoeksema et al., 1993). However, the association between the two variables seems dampened in old age, which is fully consistent with the reduced affective reactivity to daily stressors among older adults. In fact, it may be the case that age-related changes in stressorrelated INTH mediate some of the age-related changes in affective reactivity to daily stressors. Given the inadequacy of crosssectional designs for evaluating longitudinal mediation (Maxwell \& Cole, 2007), longitudinal and experimental research designs are needed to test the predictions regarding age-related changes.

More generally, the assumed underlying causal structure of the daily relations between stressors, affect, and intrusive thoughts needs to be treated with caution. High levels of negative affect may capture attention (Nolen-Hoeksema et al., 1993), leading to intrusive thoughts about an aversive state and the need for mood repair. Negative affect may also function as a signal indicating relevance of an event (Carver \& Scheier, 1999), which in turn increases concern in the form of intrusive thoughts. Third, intrusive thoughts and negative affect may be characterized by a reciprocal relationship (Moberly \& Watkins, 2008). Thus, the direction of the process relating intrusive thoughts and negative affect cannot be inferred from the analyses presented here.

\section{Relations Among Variables at Different Levels of Analysis}

This study's findings are also interesting from a conceptualmethodological point of view. Some results generated at different levels of analysis (between- and within-person level) led to the same conclusions (intrusive thoughts are associated with negative affect, between and within individuals). However, this observation did not always apply. Specifically, even though older adults had lower levels of unspecific INTH than younger adults, their increase in unspecific INTH on days with stressors was comparable to younger adults'. This emphasizes the importance of studying within-person processes in addition to identifying between-person differences (Molenaar, 2004; Schmitz, 2000).

In addition, this study provides initial glimpses at interindividual differences in the relations under investigation (variations in intraindividual correlation coefficients, significant random coefficients in multilevel models). Possibly, these differences point to the idiographic nature of the linkages between daily stressors, affect, and intrusive thoughts. Therefore, it is desirable that future studies also investigate within-person phenomena using person-centered approaches (e.g., P-technique or dynamic factor analysis; Molenaar \& Nesselroade, 2009; Nesselroade \& Schmidt McCollam, 2000).

\section{Limitations and Future Directions}

Like other investigations, we interpreted emotional reactivity partly as a proxy for emotion regulation processes. A single assessment of affect is not sufficient to capture reactivity as a 
process and to make inferences about regulation, however. To actually capture emotion regulation in relation to daily events, momentary assessments outside the laboratory may be more appropriate (Riediger, Schmiedek, Wagner, \& Lindenberger, 2009; Stawski et al., 2008; Stone, Shiffman, \& DeVries, 1999). A repeated observation of affect in short intervals and close to events would overcome difficulties in differentiating between lower reactivity and faster up-regulation of mood disturbance. Furthermore, research on reactivity and aging should include measures of emotion regulation, in a similar vein as a recent study that related emotion regulation to well-being (Kessler \& Staudinger, 2009).

Future studies would also profit from accommodating the theoretically important temporal sequence among stressor occurrence, affect, and intrusive thoughts in design and analyses. Disentangling the role of intrusive thoughts in affect and the role of affect in intrusive thoughts requires lead-lag analyses of relationships between the two variables. Furthermore, the best way to analyze maladaptive outcomes versus long-term benefits of intrusive thoughts would be to investigate their differential relations to outcomes that vary in proximity (cf. Bolger, DeLongis, Kessler, \& Schilling, 1989).

Finally, the conceptual ideal of measuring coping as a transactional process and in context (Lazarus, 2000; Tennen et al., 2000) remains to be realized, as contextual variation, specifically in stressor types, and potential age specific meanings of context were not taken into consideration in this study. For example, healthrelated daily stressors might reflect rather minor challenges for older, but not for younger adults if illness is scaled more conservatively with advancing adult age, reflecting the greater prevalence of chronic ailments.

\section{Conclusion}

Negative affect and intrusive thoughts increased on days when participants were exposed to a stressor, and the three variables all interacted with one another, implying the identification of variables important in dynamic and transactional stress-coping processes that are meaningful to both younger and older adults. We found that the coupling between stressors and negative affect was smaller in older than in younger adults, which is in accordance with developmental theories suggesting improved emotion regulation in older adults (Carstensen et al., 2003), but at odds with some other empirical findings. We also found reduced levels of intrusive thoughts in older adults, a dampened relationship between intrusive thoughts and negative affect in older adults, and a smaller within-person moderation of affective reactivity to stressors by stressor-related intrusive thoughts in older adults. In line with theories on emotional development, we tentatively conclude that normal aging dampens the stress-induced link between intrusive thoughts and negative affect. Reduced relationships between intrusive thoughts and negative affect as well as reduced affective reactivity in older adults can perhaps be explained by a changing meaning of intrusive thoughts across the adult lifespan. A potential causal role of intrusive thoughts for age differences in affective experiences in general, and for stress-affect couplings in particular, remains to be examined.

\section{References}

Aldwin, C. M. (1994). Stress, coping, and development: An integrative perspective. New York: Guilford Press.
Almeida, D. M., Wethington, E., \& Kessler, R. C. (2002). The Daily Inventory of Stressful Experiences: An interview-based approach for measuring daily stressors. Assessment, 9, 41-55.

Baltes, P. B. (1987). Theoretical propositions of life-span developmental psychology: On the dynamics between growth and decline. Developmental Psychology, 23, 611-626. doi:10.1037/0012-1649.23.5.611

Birditt, K. S., Fingermann, K. L., \& Almeida, D. M. (2005). Age differences in exposure and reactions to interpersonal tensions: A daily diary study. Psychology and Aging, 20, 330-340. doi:10.1037/08827974.20.2.330

Blanchard-Fields, F. (2007). Everyday problem solving and emotion. Current Directions in Psychological Science, 16, 26-31. doi:10.1111/ j.1467-8721.2007.00469.x

Bolger, N., DeLongis, A., Kessler, R. C., \& Schilling, E. A. (1989). Effects of daily stress on negative mood. Journal of Personality and Social Psychology, 57, 808-818. doi:10.1037/0022-3514.57.5.808

Bolger, N., \& Zuckerman, A. (1995). A framework for studying personality in the stress process. Journal of Personality and Social Psychology, 69, 890-902. doi:10.1037/0022-3514.69.5.890

Brandtstädter, J., Wentura, D., \& Rothermund, K. (1999). Intentional self-development through adulthood and later life: Tenacious pursuit and flexible adjustment of goals. In J. Brandtstädter \& R. M. Lerner (Eds.), Action and self-development: Theory and research through the life-span (pp. 373-400). Thousand Oaks, CA: Sage.

Brewin, C. R., Christodoulides, J., \& Hutchinson, G. (1996). Intrusive thoughts and intrusive memories in a nonclinical sample. Cognition and Emotion, 10, 107-112. doi:10.1080/026999396380411

Brosschot, J. F., Gerin, W., \& Thayer, J. F. (2006). Worry and health: The perseverative cognition hypothesis. Journal of Psychosomatic Research, 60, 113-124.

Carstensen, L. L., Fung, H. H., \& Charles, S. T. (2003). Socioemotional selectivity theory and the regulation of emotion in the second half of life. Motivation and Emotion, 27, 103-123. doi:10.1023/A:1024569803230

Carstensen, L. L., Mayr, U., Pasupathi, M., \& Nesselroade, J. R. (2000). Emotional experience in everyday life across the adult life span. Journal of Personality and Social Psychology, 79, 644-655. doi:10.1037/00223514.79.4.644

Carver, C. S., \& Scheier, M. F. (1999). Stress, coping, and self-regulatory process. In L. A. Pervin \& O. P. John (Eds.), Handbook of personality (pp. 553-575). New York: Guilford Press.

Charles, S. T., \& Carstensen, L. L. (2007). Emotion regulation and aging. In J. J. Gross (Ed.), Handbook of emotion regulation (pp. 307-327) New York: Guilford Press.

Charles, S. T., Piazza, J. R., Luong, G., \& Almeida, D. M. (2009). Now you see it, now you don't: Age differences in affective reactivity to social tensions. Psychology and Aging, 24, 645-653. doi:10.1037/a0016673

Erskine, J. A. S., Kvavilashvili, L., Conway, M. A., \& Myers, L. (2007). The effects of age on psychopathology, well-being and repressive coping. Aging and Mental Health, 11, 394-404. doi:10.1080/ 13607860600963737

Folkman, S., Lazarus, R. S., Pimley, S., \& Novacek, J. (1987). Age differences in stress and coping processes. Psychology and Aging, 2, 171-184.

Folkman, S., \& Moskowitz, J. T. (2004). Coping: Pitfalls and promise. Annual Review of Psychology, 55, 745-774. doi:10.1146/annurev .psych.55.090902.141456

Giambra, L. M. (1989). Task-unrelated thought frequency as a function of age: A laboratory study. Psychology and Aging, 4, 136-143. doi: 10.1037/0882-7974.4.2.136

Gross, J. J., Carstensen, L. L., Pasupathi, M., Tsai, J., Götestam Skorpen, C., \& Hsu, A. Y. C. (1997). Emotion and aging: Experience, expression, and control. Psychology and Aging, 12, 590-599. doi:10.1037/08827974.12.4.590

Hasher, L., \& Zacks, R. T. (1988). Working memory, comprehension, and 
aging: A review and a new view. In G. H. Bower (Ed.), The psychology of learning and motivation: Advances in research and theory (Vol. 22, pp. 193-225). San Diego, CA: Academic Press.

Horowitz, M. J. (1985). Disasters and psychological responses to stress. Psychiatric Annals, 15, 161-167.

Horowitz, M. J., Wilner, N., \& Alvarez, W. (1979). Impact of event scale: A measure of subjective stress. Psychosomatic Medicine, 41, 209-218.

Janke, W., \& Erdmann, G. (2002). SVF 78. Eine Kurzform des Stressverarbeitungsfragebogens SVF 120 [A short version of the Stress-CopingInventory 120]. Göttingen: Hogrefe.

John, O. P., \& Gross, J. J. (2004). Healthy and unhealthy emotion regulation: Personality processes, individual differences, and lifespan development. Journal of Personality, 72, 1301-1334. doi:10.1111/j.14676494.2004.00298.x

Kessler, E.-M., \& Staudinger, U. (2009). Affective experience in adulthood and old age: The role of affective arousal and perceived affect regulation. Psychology and Aging, 24, 349-362. doi:10.1037/a0015352

Kliegl, R., \& Lindenberger, U. (1993). Modeling intrusions and correct recall in episodic memory: Adult age differences in encoding of list context. Journal of Experimental Psychology: Learning, Memory, and Cognition, 19, 617-637. doi:10.1037/0278-7393.19.3.617

Kuhl, J., \& Baumann, N. (2000). Self-regulation and rumination: Negative affect and impaired self-accessibility. In W. J. Perrig \& A. Grob (Eds.), Control of human behavior, mental processes, and consciousness: Essays in honor of the 60th birthday of August Flammer (pp. 283-305). Mahwah, NJ: Lawrence Erlbaum Associates.

Kunzmann, U., Little, T. D., \& Smith, J. (2000). Is age-related stability of subjective well-being a paradox? Cross-sectional and longitudinal evidence from the Berlin Aging Study. Psychology and Aging, 15, 511526. doi:10.1037/0882-7974.15.3.511

Labouvie-Vief, G. (2003). Dynamic integration: Affect, cognition, and the self in adulthood. Current Directions in Psychological Science, 12, 201-206. doi:10.1046/j.0963-7214.2003.01262.x

Lachman, M. E. (1986). Locus of control in aging research: A case for multidimensional and domain-specific assessment. Psychology and Aging, 1, 34-40. doi:10.1037/0882-7974.1.1.34

Lawton, M. P., Katz, I. R., \& Nesselroade, J. R. (1996). Affective states in normal and depressed older people. Journal of Gerontology: Psychological Sciences, 6B, 309-316.

Lawton, M. P., Kleban, M. H., Rajagopal, D., \& Dean, J. (1992). Dimensions of affective experience in three age groups. Psychology and Aging, 7, 171-184. doi:10.1037/0882-7974.7.2.171

Lazarus, R. S. (2000). Toward better research on stress and coping. American Psychologist, 55, 665-673. doi:10.1037/0003-066X.55.6.665

Lazarus, R. S., \& Folkman, S. (1984). Stress, appraisal, and coping. New York: Springer.

Lindenberger, U., \& von Oertzen, T. (2006). Variability in cognitive aging: From taxonomy to theory. In E. Bialystok \& I. M. Craik (Eds.), Lifespan cognition: Mechanisms of change (pp. 279-314). Oxford, United Kingdom: Oxford University Press.

Lyubomirsky, S., Kasri, F., \& Zehm, K. (2003). Dysphoric rumination impairs concentration on academic tasks. Cognitive Therapy and Research, 27, 309-330. doi:10.1023/A:1023918517378

Lyubomirsky, S., Sousa, L., \& Dickerhoof, R. (2006). The costs and benefits of writing, talking, and thinking about life's triumphs and defeats. Journal of Personality and Social Psychology, 90, 692-708. doi:10.1037/0022-3514.90.4.692

Lyubomirsky, S., \& Tkach, C. (2004). The consequences of dysphoric rumination. In C. Papageorgiou \& A. Wells (Eds.), Rumination: Nature, theory, and treatment of negative thinking in depression (pp. 21-41). Chichester, England: Wiley.

Martin, L. L., Tesser, A., \& McIntosh, D. (1993). Wanting but not having: The effects of unattained goals on thoughts and feelings. In D. M.
Wegner \& J. W. Pennebaker (Eds.), Handbook of mental control (pp. 552-572). Englewood Cliffs, NJ: Prentice Hall.

Maxwell, S. E., \& Cole, D. A. (2007). Bias in cross-sectional analyses of longitudinal mediation. Psychological Methods, 12, 23-44. doi:10.1037/ 1082-989X.12.1.23

McConatha, J. T., Leone, F. M., \& Armstrong, J. M. (1997). Emotional control in adulthood. Psychological Reports, 80, 499-507.

Moberly, N. J., \& Watkins, E. R. (2008). Ruminative self-focus and negative affect: An experience sampling study. Journal of Abnormal Psychology, 117, 314-323. doi:10.1037/0021-843X.117.2.314

Molenaar, P. C. M. (2004). A manifesto on psychology as idiographic science: Bringing the person back into scientific psychology, this time forever. Measurement, 2, 201-218.

Molenaar, P. C. M., \& Nesselroade, J. R. (2009). The recoverability of P-technique factor analysis. Multivariate Behavioral Research, 44, 130141. doi:10.1080/00273170802620204

Moogle, J. A., Stawski, R. S., \& Sliwinski, M. J. (2008, April). Intraindividual variability in cognitive interference in older adults. Poster presented at the Cognitive Aging Conference 2008, Atlanta, GA.

Mroczek, D. K., \& Almeida, D. M. (2004). The effect of daily stress, personality, and age on daily negative affect. Journal of Personality, 72, 355-378. doi:10.1111/j.0022-3506.2004.00265.x

Nesselroade, J. R., \& Schmidt McCollam, K. M. (2000). Putting the process in developmental processes. International Journal of Behavioral Development, 24, 295-300. doi:10.1080/01650250050118277

Neupert, S. D., Almeida, D. M., \& Charles, S. T. (2007). Age differences in reactivity to daily stressors: The role of personal control. Journal of Gerontology: Psychological Sciences, 62B, P216-P225

Nezlek, J. B. (2005). Distinguishing affective and non-affective reactions to daily events. Journal of Personality, 73, 1539-1568. doi:10.1111/ j.1467-6494.2005.00358.x

Nolen-Hoeksema, S., Morrow, J., \& Fredrickson, B. (1993). Response styles and the duration of episodes of depressed mood. Journal of Abnormal Psychology, 102, 20-28. doi:10.1037/0021-843X.102.1.20

Nolen-Hoeksema, S., Wisco, B. E., \& Lyubomirsky, S. (2008). Rethinking rumination. Perspectives on Psychological Science, 3, 400-424. doi: 10.1111/j.1745-6924.2008.00088.x

Ong, A. D., Bergeman, C. S., Bisconti, T. L., \& Wallace, K. A. (2006) Psychological resilience, positive emotions, and successful adaptation to stress in later life. Journal of Personality and Social Psychology, 91, 730-749. doi:10.1037/0022-3514.91.4.730

Rachman, S. (1981). Unwanted intrusive cognitions. Advances in Behaviour Research and Therapy, 3, 89-99. doi:10.1016/0146-6402(81)90007-2

Riediger, M., Schmiedek, F., Wagner, G. G., \& Lindenberger, U. (2009). Seeking pleasure and seeking pain: Age-related differences in pro- and contra-hedonic motivation from adolescence to old age. Psychological Science, 20, 1529-1535. doi:10.1111/j.1467-9280.2009.02473.x

Röcke, C., Li, S.-C., \& Smith, J. (2009). Intraindividual variability in positive and negative affect over 45 days: Do older adults fluctuate less than young adults? Psychology and Aging, 24, 863-878. doi:10.1037/a0016276

Schmiedek, F., Bauer, C., Lövdén, M., Brose, A., \& Lindenberger, U. (2010). Cognitive enrichment in old age: Web-based training programs. GeroPsych, 23, 59-67.

Schmiedek, F., Lövdén, M., \& Lindenberger, U. (2010). On the relation of mean reaction time and intraindividual reaction time variability. Psychology and Aging, 24, 841-857. doi:10.1037/a0017799

Schmitz, B. (2000). Auf der Suche nach dem verlorenen Individuum: Vier Theoreme zur Aggregation von Prozessen [Searching for the lost individual: Four theorems to aggregate processes]. Psychologische Rundschau, 51, 83-92. doi:10.1026//0033-3042.51.2.83

Segerstrom, S. C., Stanton, A. L., Alden, L. E., \& Shortridge, B. E. (2003). A multidimensional structure for repetitive thought: What's on your mind, and how, and how much? Journal of Personality and Social Psychology, 85, 909-921. doi:10.1037/0022-3514.85.5.909 
Singer, J. D., \& Willett, J. B. (2003). Applied longitudinal data analysis: Modeling change and event occurrence. New York: Oxford University Press.

Skinner, E. A. (2001). Coping across the lifespan. In N. J. Smelser \& P. B. Baltes (Eds.), International encyclopedia of the social and behavioral sciences (pp. 2761-2766). Amsterdam: Elsevier.

Sliwinski, M. J., Almeida, D. M., Smyth, J., \& Stawski, R. S. (2009). Intraindividual change and variability in daily stress processes: Findings from two measurement-burst diary studies. Psychology and Aging, 24, 828-840. doi:10.1037/a0017925

Stawski, R. S., Almeida, D. M., Lachman, M. E., Tun, P. A., \& Rosnick, D. B. (2010). Fluid cognitive ability is associated with greater exposure and smaller reactions to daily stressors. Psychology \& Aging, 25, 330342. doi: $10.1037 / \mathrm{a} 0018246$

Stawski, R. S., Sliwinski, M. J., Almeida, D. M., \& Smyth, J. M. (2008). Reported exposure and emotional reactivity to daily stressors: The roles of adult age and global perceived stress. Psychology and Aging, 23, 52-61. doi:10.1037/0882-7974.23.1.52

Stone, A. A., \& Neale, J. M. (1984). Effects of severe daily events on mood. Journal of Personality and Social Psychology, 46, 137-144. doi:10.1037/0022-3514.46.1.137

Stone, A. A., Shiffman, S. S., \& DeVries, M. W. (1999). Ecological momentary assessment. In D. Kahneman, E. Diener \& N. Schwarz (Eds.), Well-being: The foundations of hedonic psychology (pp. 26-39). New York: Russell Sage Foundation.
Tennen, H., Affleck, G., Armeli, S., \& Carney, M. A. (2000). A daily process approach to coping. American Psychologist, 55, 626-636. doi: 10.1037/0003-066X.55.6.626

Uchino, B. N., Berg, C. A., Smith, T. W., Pearce, G., \& Skinner, M. (2006). Age-related differences in ambulatory blood pressure during daily stress: Evidence for greater blood pressure reactivity with age Psychology and Aging, 21, 231-239. doi:10.1037/0882-7974.21.2.231

Watson, D., Clark, L. A., \& Tellegen, A. (1988). Development and validation of brief measures of positive and negative affect: The PANAS scales. Journal of Personality and Social Psychology, 54, 1063-1070. doi:10.1037/0022-3514.54.6.1063

Wrosch, C., \& Heckhausen, J. (2002). Peceived control of life regrets: Good for young and bad for old adults. Psychology and Aging, 17, $340-350$.

Zautra, A. J. (2003). Emotions, stress, and health. New York: Oxford University Press.

Zautra, A. J., Affleck, G., \& Tennen, G. (1994). Assessing life events among older adults. In M. P. Lawton \& J. A. Teresi (Eds.), Annual review of gerontology and geriatrics: Focus on assessment techniques (pp. 324-352). New York: Springer.

Received June 2, 2010

Revision received October 27, 2010

Accepted November 3, 2010 